\title{
A review of pulsed electromagnetic field (PEMF) mechanisms at a cellular level: a rationale for clinical use
}

\author{
Brett Wade
}

Therapist Assistant Program, Okanagan College, Kelowna, British Columbia, Canada

Email address:

bwade@okanagan.bc.ca

\section{To cite this article:}

Brett Wade. A Review of Pulsed Electromagnetic Field (PEMF) Mechanisms at a Cellular Level: A Rationale for Clinical Use. American Journal of Health Research. Vol. 1, No. 3, 2013, pp. 51-55. doi: 10.11648/j.ajhr.20130103.13

\begin{abstract}
Delivery of health care demands evidence-based practice. Evidence-based practice helps to ensure that all facets of health care delivery are subject to a higher level of accountability. This helps to assure that the patient is receiving treatment that has some proof of efficacy. In recent years, physiotherapy practice has been influenced by a swell of research which, in many cases, supports current practice and, in some cases, influences change of practice. Despite the fact that there is a significant increase in the numbers of clinical trials and reviews in Physiotherapy, including research in electromagnetic modalities and mechanical modalities, it is not uncommon for a practitioner to feel at a loss to answer, "Exactly how does this treatment work?" This paper will review the mechanisms of action of the most common electromagnetic modalities and provide a rationale as to why "pulsed" fields seem to produce more significant effects compared with continuous applications. It will be shown that significant tissue healing effects, particularly with the modality PEMF, are likely the result of increased activity in non-excitable cells. The reputation of electromagnetic modalities has suffered in recent years, likely due to a lack of understanding of mechanisms for action. In the literature, the understanding in this area has made considerable progress over the past ten years. This review will explain the science at a cellular level and suggest the potential mechanisms for action for the modalities with specific focus on PEMF.
\end{abstract}

Keywords: Pulsed Electromagnetic Fields, Physiotherapy, Modalities, Mechanism of Action

\section{Introduction}

Electromagnetic modalities include any modality which uses electricity and therefore generates both an electric field and a magnetic field. This includes, but is not limited to: transcutaneous electrical nerve stimulation (TENS), interferential current (IFC), neuromuscular electrical stimulation (NMES), high voltage pulsed galvanic (HVPG), and pulsed electromagnetic fields (PEMF). Ultrasound, a commonly used modality in which the resultant acoustic wave is a mechanical wave, is not an electromagnetic modality and will therefore not be included in this discussion. There are other electromagnetic modalities in use such as percutaneous electrical nerve stimulation (PENS), microcurrent therapy (MCT), microwave diathermy (MWD), Russian stimulation, etc, and these modalities will not be addressed due to their relative lower utilization in clinical settings in North America.

Electromagnetic radiation is the flow of electricity (movement of electrons) and the coupled magnetic field that is generated by the movement of electrons. This movement of electrons may occur in waves (having a frequency) or occur as a static flow of electrons with the resultant magnetic field. Electromagnetic radiation can be divided into two main categories: ionizing and non-ionizing radiation. The dividing line between ionizing and non-ionizing is a critical point in both frequency and intensity whereby with ionizing radiation has sufficient energy to dislodge an electron from an atom or a molecule. Examples of ionizing radiation are ultraviolet (C), X-Rays, and gamma radiation. Examples of non-ionizing radiation are: Ultraviolet ( $\mathrm{B}$ and $\mathrm{A}$ ), microwaves, infrared, and radio waves.

In physiotherapy practice, these electromagnetic modalities are generally used to expedite recovery of soft tissue injuries or alleviate pain. With some modalities the theory and intention is that the electrical field is used directly, such as with TENS, NMES, HVPG, or IFC. These modalities create an electrical field in the form of a direct current that runs between the electrodes. This movement of electrons is intended to affect the cellular physiology of excitable cells. The movement of the electrons will cause ions to move towards the electrodes and thereby, ostensibly, 
affecting the physiology of the cell. Ions such as calcium $\left(\mathrm{Ca}^{2+}\right)$, potassium $\left(\mathrm{K}^{+}\right)$, sodium $\left(\mathrm{Na}^{+}\right)$, chlorine $\left(\mathrm{Cl}^{-}\right)$, etc. flow towards the electrode in which they are most strongly attracted. Negative ions such as chlorine will be attracted to the positive pole (anode), and positive ions such as potassium will be attracted to the negative pole (cathode). The levels of stimulation achieved with stimulating excitable cells are generally categorized as sub sensory, sensory, motor, and noxious (2).

Ions have numerous roles in the cellular physiology of cells (see Table 1). The movement of ions through ion channels in the plasma membrane and organelles have important roles in excitable and non-excitable cells such as nerve cell signal propagation, muscle contractions, energy production, etc. Electrotherapy education has traditionally attributed the positive effects of electrotherapy to the effects of an electric current causing a depolarization of excitable cells by the forced movement of ions $(\mathrm{Na}+$ and $\mathrm{K}+)$ across the plasma membrane. A review of several electrotherapy textbooks demonstrates that the theory espoused for electrotherapy is based on the view that the main effects are due to the depolarization of excitable cells. Also of note, the texts do not include theories related to the effects of the magnetic field, and in particular the background theory as to why a pulsed field may have a greater therapeutic effect than a non-pulsed field.

Table 1. Summary of Ion Functions in Excitable Cells.

\begin{tabular}{lll}
\hline Ion & \multicolumn{2}{l}{ Function(s) } \\
\hline & - & Muscle contraction \\
& - & Secondary messenger \\
Calcium $\left(\mathrm{Ca}^{2+}\right)$ & Facilitate neurotransmitter or release \\
& - & Gene transcription \\
& Generate action potential \\
Sodium $\left(\mathrm{Na}^{2+}\right)$ & Generate action potential \\
Potassium $\left(\mathrm{K}^{+}\right)$ & - & Generate action potential \\
Chloride $\left(\mathrm{Cl}^{-}\right)$ & - & Generate action potential \\
\hline
\end{tabular}

As previously described, negatively anions such as $\mathrm{Cl}^{-}$ will, in theory, be attracted to the positive charge of the externally applied electrode and positively charged ions such as $\mathrm{Na}^{+}$and $\mathrm{K}^{+}$will be attracted to the negative electrode. If the current used is a simple direct current (electrons flowing only in one direction), there would be build up of same-charge ions concentrating in one area. This would have a significant effect on local $\mathrm{pH}$ due to increased concentrations of hydrochloric acid and sodium hydroxide leading to cause pain and cellular damage. Therefore, electrotherapy is usually the use of a direct current that is both pulsed and bi-directional to prevent excessive build-up of ions under an electrode. A paper published by Panagopoulos et al. (3) suggested a hypothesis whereby the externally applied electromagnetic field causes the ions to vibrate and when this vibration reaches a critical point, this gives a false signal to the voltage gated channels present in the membranes of eukaryotic cells. Once the voltage gated channel receives a false signal, the gate may be forced to either open or perhaps close but theoretically affecting the physiology of the cell.

Panagopoulos et al. further describe how both the oscillating electric and magnetic fields can have similar effects on the free ions and consequently the voltage gated channels. It has long been argued that low frequency; non-ionizing radiation has no significant bioactive effects on cells. This, in fact, has been the argument for why wireless technology and the use of cellular telephones should have no negative effects to human health. The theory presented by Panagopoulos et al. suggests that, because of the inverse relationship between amplitude of the "ion's forced vibration" and frequency, lower frequency electromagnetic fields have the potential to be more bioactive. The authors provide a mathematical model which also explains how pulsed fields (on for a period and off for a period) are more bioactive than static fields of the same parameters, and their calculations demonstrate how either pulsed electromagnetic fields or the time of onset or removal of an external field will be twice as active as non-pulsatile fields. The calculations support other observations which have found bioactive effects with pulsed fields of extremely low frequency.

While any of the electromagnetic modalities can theoretically attribute their effects to both the electric and magnetic field, only PEMF is designed specifically to direct magnetic fields through the tissues to facilitate healing. The purported mechanism of action of magnetic fields on cells is has been suggested by Panagopoulos et al. Another paper by Ganesan et al. (4) reviewed the literature for PEMF in the treatment of arthritis. In addition to the effects suggested by Panagopoulos et al., Ganesan et al., suggest that $\mathrm{Ca} 2+$ may be modulated by the externally applied magnetic field which in turn could affect many important aspects of cell physiology including gene activation, signal transduction, cAMP production, immune function, etc. Looking specifically at the effects of a pulsed magnetic field related to arthritis, Ganesan et al., review research which has found increased chondrocyte production in joints exposed to PEMF. The authors also review research which demonstrates a decrease in pro-inflammatory cytokines such as TNF-alpha and IL-6. In vitro studies have also demonstrated that PEMF has significant effects on both excitable and non-excitable cells leading to osteogenesis (5) and chondrocyte proliferation (6). The research into positive effects with PEMF and multiple sclerosis (MS) has found beneficial effects from PEMF using much weaker intensities (7). Sandyk has shown positive results with MS in the picotesla intensities (8)

If the electric field is created by a movement of electrons, the resultant magnetic field is also capable of inducing electric currents in a surrounding medium. The magnetic field created by the moving electrons is essentially a field of virtual photons creating force lines. This magnetic field is capable of causing movement of particles with an electric charge such as ions. This force is known as a Lorentz force. Since PEMF is not using an electric field per se, there is no 
electron flow with frequency and pulse width suitable for stimulating sensory or motor nerves. What the electric field and the magnetic field have in common is the forced movement of ions. If an externally applied electromagnetic field can cause the forced movement of ions across a plasma membrane and we know that these movements can affect cellular physiology, are there "windows" of frequency and intensity which may be more effective? The parameters which have shown to be the most effective with PEMF in treating pathologies such as: bone healing, wound healing, ligament healing, and cartilage healing range from $15-75 \mathrm{~Hz}$ and use intensities in the militesla range. Markov (9) has suggested "three amplitude windows" with PEMF: 50-100 $\mu \mathrm{T}, 15-20 \mathrm{mT}$, and 45-50 mT. Summarized in Table 2 are some of the effects on non-excitable cells exposed to PEMF.

Table 2: Non-Excitable Cellular Reactions to PEMF

\begin{tabular}{|c|c|c|c|}
\hline Cells & Mechanism & parameters & References \\
\hline Chondrocytes & Increased number of chondrocytes & $75 \mathrm{~Hz}, 2.3 \mathrm{mT}$ & (6) \\
\hline Osteoblasts & Increased proliferation of osteoblasts & $15 \mathrm{~Hz}, 0.1 \mathrm{mT}$ & $(5)$ \\
\hline Osteoclasts & Decreased production of osteoclasts & $7.5 \mathrm{~Hz}, 300 \mu \mathrm{s}$ & \\
\hline Neutrophils & Saturates adenosine receptors leading to decreased inflammatory cytokine cascade & $75 \mathrm{~Hz}, 0.2 \mathrm{mT}-3.5 \mathrm{mT}$ & $(10)$ \\
\hline Mononuclear & Significant increases in IL-1 $\beta$ and TNF- $\alpha$ (Pro inflammatory cytokines) & $50 \mathrm{~Hz}, 2.25 \mathrm{mT}$ & $(11)$ \\
\hline Fibroblasts & Reduction of cAMP leads to increased proliferation of collagen cells & $15 \mathrm{~Hz}, 4.8 \mathrm{~ms}$ pulse & $(12)$ \\
\hline Endothelial & Increased proliferation of endothelial cells leading to angiogenesis. & $50 \mathrm{~Hz}, 1 \mathrm{mT}$ & (13) \\
\hline
\end{tabular}

There are numerous manufacturers of PEMF machines. Some manufactures promote and sell a version whereby the patient lies on a mat and other manufacturers utilize a more direct application specific to a body part. In general, the PEMF mats use frequencies that range from 5-300 Hz which is generally classified in a range of electromagnetic frequencies known as extremely low frequency (ELF). The magnetic field intensities used by these machines are usually in the micro and millitesla range. The research into the effects of PEMF is somewhat equivocal. Some in vivo research has shown positive effects with conditions such as arthritis, bone healing, cartilage healing, nerve regeneration, wound healing, and multiple sclerosis. It is common to notice weak methodological reporting in some of the in vivo studies. Summarized in Table 3 are some conditions which have shown to be beneficial in the treatment of various conditions.

Table 3. Conditions which have been shown to benefit from PEMF

\begin{tabular}{ll}
\hline Condition & Reference \\
\hline Multiple Sclerosis & $(7)$ \\
Osteoarthritis of the Knee & $(14)$ \\
Fibromyalgia & $(15)$ \\
Loosened Hip Prostheses & $(16)$ \\
Cervical osteoarthritis & $(17)$ \\
Lateral epicondylitis & $(18)$ \\
Pain of rheumatoid arthritis and fibromyalgia. & $(19)$ \\
Congenital Pseudoarthrosis & $(20)$ \\
Cervical and knee pain due to osteoarthritis & $(21)$ \\
Delayed union tibial fractures & $(22)$ \\
Chronic rotator cuff tendinitis & $(23)$ \\
Osteoporosis & $(24)$ \\
Osteonecrosis of the hip & $(25)$ \\
Chronic venous ulcers & $(26)$ \\
\hline
\end{tabular}

\section{Summary}

The research to date has shown that the mechanisms by which PEMF works are complicated and likely involve many pathways. It is clear that certain windows of frequency and intensity are capable of increasing mitosis in cells such as chondrocytes, osteoblasts, fibrocytes and endothelial cells. These effects, as shown in Table 3, will lead to improved healing time of soft tissues and bone. In addition to increasing cell metabolism, perhaps PEMF's greatest power is in its ability to ameliorate the effects of inflammation by decreasing inflammatory cytokines. This effect should give the practitioner cause to consider PEMF in the treatment of numerous inflammatory conditions including, perhaps, autoimmune diseases such as MS.

While not discussed specifically in this paper, it is also conceivable, as suggested by Gordon (27), that another important effect of PEMF is the ability of the magnetic fields to restore "equilibrium in ROS (free radical)/antioxidant chemistry. Gordon explains that since both reactive oxygen species (ROS) free radicals such as superoxide anion $\left(\mathrm{O}^{2-}\right)$ and hydroxyl anion $\left(\mathrm{OH}^{-}\right)$are paramagnetic, they will be affected by a magnetic field. This forced vibration (similar to the effect on ions such as $\mathrm{K}^{+}, \mathrm{Na}^{+}, \mathrm{Cl}^{-}, \mathrm{Ca}^{2+}$ ) is thought to enhance the homeostasis between ROS and antioxidants. It is unequivocal that all chronic diseases result from a lack of homeostasis between free radicals and antioxidants. While both free radicals and antioxidants are normal and vital for processes such as cellular respiration and immunity, an imbalance could lead to cell and tissue death, DNA damage, and protein and fat degradation.

If PEMF is shown to be clinically effective in many conditions (Table 3), it is curious why the modality is not used more regularly in physiotherapy practice today. 
Gordon (27) in his review article on PEMF clinical applications, describes the complicated history of this modality. Gordon describes how the Flexner Report in 1910 which recommended changes in medical school training designated PEMF as "irregular science" and had it expunged from medical school training in the United States and Canada. Prior to this time, PEMF was widely used and with great success in the $19^{\text {th }}$ and early $20^{\text {th }}$ century. These primitive electromagnetic therapeutic devices were used by both medical doctors and non-allopathic health practitioners. The Flexner report caused the dissolution of any medical training that did not emphasize science and pharmaceutical approaches. Medical schools that taught courses in electromagnetism, Eastern medicine, homeopathy, etc received no funding and, as a result, either conformed or dissolved.

Of course the Flexner report made significant improvements in the quality and standardization of medical training, but at the expense of cutting and vilifying some effective forms of therapy such as PEMF. In a sense, physiotherapy practice in Canada and the United States has gone through its own form of purging of electrotherapy from its own practice. While some skepticism is a good thing, thanks to the development of quantum theories of physics and a renewed interest in electromagnetism as a powerful modality, we are seeing that research not only supports its use but the mechanisms are becoming elucidated.

It is important to note that many of the journals in which positive effects from PEMF are noted are not necessarily Physiotherapy journals. Much of the aforementioned research is from journals related to the fields of Rheumatology, Orthopaedics, and Neurology. While many Physiotherapists have wanted to distance themselves from the use of electromagnetic modalities, it cannot be denied that research is proving some of these modalities to be highly effective for many conditions. If the medical community wants to refer patients for treatment for effective electromagnetic modalities such as PEMF, physiotherapists, with their training and knowledge, are the best practitioners to deliver such treatment as an adjunct to manual techniques and therapeutic exercise prescription.

\section{References}

[1] Behrens B, Michlovitz S. Physical Agents Theory and Practice. Second ed. Philadelphia: F.A. Davis; 2006. p. 145

[2] Panagopoulos DJ, Karabarbounis A, Margaritis LH. Mechanism for action of electromagnetic fields on cells. Biochemical and Biophysical Research Communications. 2002;298(1):95-102.

[3] Ganesan K, Gengadharan AC, Balachandran C, Manohar BM, Puvanakrishnan R. Low frequency pulsed electromagnetic field--a viable alternative therapy for arthritis. Indian J Exp Biol. 2009;47(12):939-48.

[4] Chang WH-S, Chen L-T, Sun J-S, Lin F-H. Effect of pulse-burst electromagnetic field stimulation on osteoblast cell activities. Bioelectromagnetics. 2004;25(6):457-65.

[5] Mattei MD, Caruso A, Pezzetti F, Pellati A, Stabellini G, Sollazzo V, et al. Effects of Pulsed Electromagnetic Fields on Human Articular Chondrocyte Proliferation. Connective Tissue Research. 2001;42(4):269-79.

[6] Richards TL, Lappin MS, Acosta-Urquidi J, Kraft GH, Heide AC, Lawrie FW, et al. Double-blind study of pulsing magnetic field effects on multiple sclerosis. J Altern Complement Med. 1997;3(1):21-9.

[7] Sandyk R. Role of the pineal gland in multiple sclerosis: a hypothesis. Journal of Alternative \& Complementary Medicine. 1997;3(3):267-90.

[8] Markov M. Pulsed electromagnetic field therapy history, state of the art and future. The Environmentalist. 2007;27(4):465-75.

[9] Varani K, Gessi S, Merighi S, Iannotta V, Cattabriga E, Spisani S, et al. Effect of low frequency electromagnetic fields on $\mathrm{A} 2 \mathrm{~A}$ adenosine receptors in human neutrophils. British Journal of Pharmacology. 2002;136(1):57-66.

[10] Gómez-Ochoa I, Gómez-Ochoa P, Gómez-Casal F, Cativiela E, Larrad-Mur L. Pulsed electromagnetic fields decrease proinflammatory cytokine secretion (IL- $1 \beta$ and TNF- $\alpha$ ) on human fibroblast-like cell culture. Rheumatology International. 2011;31(10):1283-9.

[11] Farndale R, Murray J. Pulsed electromagnetic fields promote collagen production in bone marrow fibroblasts via athermal mechanisms. Calcified Tissue International. $1985 ; 37(2): 178-82$.

[12] Delle Monache S, Alessandro R, Iorio R, Gualtieri G, Colonna R. Extremely low frequency electromagnetic fields (ELF-EMFs) induce in vitro angiogenesis process in human endothelial cells. Bioelectromagnetics. 2008;29(8):640-8.

[13] Pipitone N, Scott DL. Magnetic pulse treatment for knee osteoarthritis: a randomised, double-blind, placebo-controlled study. Curr Med Res Opin. 2001;17(3):190-6.

[14] Sutbeyaz ST, Sezer N, Koseoglu F, Kibar S. Low-frequency pulsed electromagnetic field therapy in fibromyalgia: a randomized, double-blind, sham-controlled clinical study. Clin J Pain. 2009;25(8):722-8.

[15] Kennedy WF, Roberts CG, Zuege RC, Dicus WT. Use of pulsed electromagnetic fields in treatment of loosened cemented hip prostheses. A double-blind trial. Clin Orthop Relat Res. 1993;286(286):198-205.

[16] Sutbeyaz ST, Sezer N, Koseoglu BF. The effect of pulsed electromagnetic fields in the treatment of cervical osteoarthritis: a randomized, double-blind, sham-controlled trial. Rheumatol Int. 2006;26(4):320-4.

[17] Uzunca K, Birtane M, Tastekin N. Effectiveness of pulsed electromagnetic field therapy in lateral epicondylitis. Clin Rheumatol. 2007;26(1):69-74.

[18] Shupak NM, McKay JC, Nielson WR, Rollman GB, Prato FS, Thomas AW. Exposure to a specific pulsed low-frequency magnetic field: a double-blind placebo-controlled study of effects on pain ratings in rheumatoid arthritis and fibromyalgia patients. Pain Res Manag. 2006;11(2):85-90. 
[19] Bassett C, Schink-Ascani M. Long-term pulsed electromagnetic field (PEMF) results in congenital pseudarthrosis. Calcified Tissue International. 1991;49(3):216-20.

[20] Trock DH, Bollet AJ, Markoll R. The effect of pulsed electromagnetic fields in the treatment of osteoarthritis of the knee and cervical spine. Report of randomized, double blind, placebo controlled trials. J Rheumatol. 1994;21(10):1903-11.

[21] Sharrard W. A double-blind trial of pulsed electromagnetic fields for delayed union of tibial fractures. Journal of Bone \& Joint Surgery, British Volume. 1990 May 1, 1990;72-B(3):347-55.

[22] Binder A, Parr G, Hazleman B, Fitton-Jackson S. PULSED ELECTROMAGNETIC FIELD THERAPY OF PERSISTENT ROTATOR CUFF TENDINITIS: A Double-blind Controlled Assessment. The Lancet. 1984;323(8379):695-8.
[23] Huang LQ, He HC, He CQ, Chen J, Yang L. Clinical update of pulsed electromagnetic fields on osteoporosis. Chin Med J. 2008;121(20):2095-9.

[24] Yoo M, Cho Y, Kim K, Chun Y, Chung C. PULSED ELECTROMAGNETIC FIELDS TREATMENT FOR THE EARLY STAGES OF OSTEONECROSIS OF THE FEMORAL HEAD. Journal of Bone \& Joint Surgery, British Volume. 2004 February 1, 2004;86-B(SUPP II):148-9.

[25] Stiller MJ, Pak GH, Shupack JL, Thaler S, Kenny C, Jondreau L. A portable pulsed electromagnetic field (PEMF) device to enhance healing of recalcitrant venous ulcers: a double-blind, placebo-controlled clinical trial. British Journal of Dermatology. 1992;127(2):147-54.

[26] Gordon GA. Designed electromagnetic pulsed therapy: Clinical applications. Journal of Cellular Physiology. 2007;212(3):579-82. 